К ВОПРОСУ ОБ ОПРЕДЕЛЕНИИ КРИТЕРИЕВ ЭФФЕКТИВНОСТИ АДМИНИСТРАТИВНО-ПРАВОВОГО РЕГУЛИРОВАНИЯ ПУБЛИЧНО-СЛУЖЕБНЫХ ОТНОШЕНИЙ

В КОНТЕКСТЕ МОДЕРНИЗАЦИИ ГОСУДАРСТВЕННОГО УПРАВЛЕНИЯ И ИННОВАЦИОННОГО РАЗВИТИЯ

$\mathrm{B}$ настоящее время гражданским обществом к государственной и муниципальной службе предъявляются значительно возросшие требования. Однако оценка профессиональной служебной деятельности государственных служащих и муниципальных служащих еще слабо увязана с тем, насколько качественно оказываются в государственном органе государственные услуги гражданам и организациям ${ }^{1}$.

В работе кадровых служб государственных органов и органов местного самоуправления все еще используются устаревшие технологии, не ведется целенаправленная работа по привлечению молодых перспективных кадров. Современные методы планирования и регламентации труда государственных служащих не получили широкого распространения, а предусмотренные законодательством РФ механизмы стимулирования государственных служащих к исполнению обязанностей государственной службы на высоком профессиональном уровне не реализуются в полной мере, что снижает мотивацию государственных служащих. Качество профрессионального обучения государственных служащих в недостаточной степени отвечает потребностям развития государственной службы.

Нужно отметить, что указанные проблемы в значительной степени связаны с отсутствием научно обоснованной и апробированной методики применения норм законодательства РФ о государ-

\footnotetext{
${ }^{1}$ См.: Костенников М.В., Куракин А.В., Марьян А.В. Административно-правовое регулирование противодействия коррупционным рискам в системе государственной службы. - Домодедово, 2011. - С. 3.
}

ственной службе. Проведение экспериментов, разработка должностных регламентов, применение новых кадровых технологий на государственной службе не имеют системного характера. Недостаточно проработана методика проведения конкурсов на замещение вакантных должностей гражданской службы, квалификационных экзаменов и аттестации государственных служащих. В должной мере не обеспечивается взаимосвязь реформы государственной службы с бюджетной, административной, судебной и военной рефоормами, рефоомой местного самоуправления и другими преобразованиями в сфере государственного управления. Недостаточная открытость публичной службы способствует проявлениям бюрократизма и коррупции ${ }^{2}$.

Как показывает исследование сущностные черты административно-правовой эфффективности модернизации деятельности государственной и муниципальных служащих. Правовые изменения в их статусе требуют обеспечения единства прав и обязанностей служащих, учета специфических особенностей и целостность государственных и муниципальных служебных правоотношений. Рефрормирование (модернизация) в сфрере публичной службы - путь укрепления, прежде всего информационных начал модернизации прав и обязанностей служащих.

Информационное общество и правовое государство определяют сущность, содержание служебного правоотношения, которое образует совокупность корреспондирующих субъективных прав

\footnotetext{
2 См.: Там же.
} 
и субъективных обязанностей государственного (муниципального) служащего и нанимателя (государства или муниципального образования).

Стратегической задачей в части развития науки административного права являются: создание сектора исследований и разработок, способного проводить исследования по актуальным для юридической науки и приоритетным для России направлениям.

К таким направлениям, определенным требованием раздела VII «эфрфективная наука стратегии инновационного развития России» относятся: повышение качества кадрового потенциала; повышение эфрфективности сектора исследований и разработок, в том числе за счет реструктуризации ряда научных и управленческих центров; наращивание исследовательского потенциала на ключевых направлениях модернизации профессиональной деятельности управленческих кадров; развитие механизмов и инструментов координации и взаимодействия всех участников инновационного процесса административно-правового обеспечения эфрфективности служебной деятельности.

Решение поставленных задач при существенном расширении за последние годы спектра используемых инструментов и механизмов развития административно-правовой науки требует значительно более четкой координации предпринимаемых на этом направлении усилий. Исходя из этого, целесообразно обеспечить развитие конкурентоспособных управленческих центров и кадровых служб, где будет концентрироваться значительная часть компетенций в сфрере прикладных исследований и разработок, в том числе за счет максимальной интеграции науки и административного права и учебных управленческих центров, обработки различных моделей их взаимодействия, в том числе в рамках расширения грантовой фрормы финансирования исследований с одновременным поэтапным сокращением доли финансирования в форме государственных, контрактов на проведение научно-исследовательских работ в сфрере подготовки и переподготовки управленческих кадров.

В области совершенствования средств административно-правовой эфрфективности модернизации служебной деятельности практики проведения комплексной оценки потенциала и результативности действующих государственных учреждений, в том числе государственных научных центров и научных учреждений, занятых подготовкой управленческих кадров. Предстоит уточнить и конкретизировать методики оценки уровня и качества научных проектов и организаций различного профриля с учетом специсрики прикладных исследований, вузовской науки, отдельных областей исследований на основе современных международных методик. Учитывая специфику профессиональной служебной деятельности управленческих кадров, проведение таких оценок должно в максимальной степени опираться на силы самого научного сообщества юристов, экономистов, социологов.

Основными критериями оценки качества результативности структурной модернизации должны международное признание системных преобразований в деятельности российских служб и служащих. Для науки административного права является востребованность результатов проводимых исследований, в том числе российскими и зарубежными административистами и органами власти различного уровня. Регламенты проведения оценки служебной деятельности управленческих кадров и принятия решений по ее итогам должны предусматривать возможность направления средств, сэкономленных за счет сокращения неэффективных подразделений на развитие самой организации профессиональной деятельности эффективных подразделений, решение проблем материально-технического обеспечения и модернизации исследовательского сектора служебных правоотношений. Предстоит реализовать комплекс мер для обеспечения качества разработки и реализации среднесрочных программ развития государственной службы, которые подлежат оценке наряду с результативностью прошлых периодов.

Процесс совершенствования служб, служащих, включая оптимизацию их состава и деятельности, будет сопровождаться созданием условий для возникновения новых правовых отношений на базе наиболее эфффективных средств инновационного развития. С этой целью следует разобрать систему выделения на создание учреждений, организаций, которые будут предусматривать фринансирование создания и материально-технического обеспечения новых организаций управленческих структур, их служащих.

Важным, направлением на первом этапе реализации Стратегии инновационного развития России является продолжение развития сети национальных исследовательских центров, которые должны стать ядром нового интегрированного научно-образовательного комплекса, обеспечивающего подготовку кадров нового, информационного направления. На втором этапе реализации Стратегии необходимо внедрить механизмы управления научными 
исследованиями, предоставляющие большую административную и финансовую автономию научным подразделениям и коллективам, функционирующим рамках административно-правового обеспечения эффрективности модернизации механизмов управления, руководители которых обладают более широкими полномочиями и большей ответственностью за выбор направлений развития, источников фринансирования и использования средств.

Как показывает анализ общих служебных прав государственных и муниципальных служащих в информационной сфере, они в большинстве случаев состоят из таких элементов, как правомочия (информационного содержания) совершать определенные действия (или воздерживаться от их совершения) и требовать реализации своих информационных прав от нанимателя. Сюда же входят правомочия информационного характера обращаться в случае необходимости за государственной защитой и правомочия на этой основе пользоваться определенными социальными благами. К таковым, например, относятся: право на обеспечение информацией, необходимой для исполнения должностных обязанностей, наряду с правом на отдых, правом на оплату труда и др.

В то же время некоторые права включают меньшее или большее число элементов (в праве на должностной рост на конкурсной основе невозможно выделить правомочие пользования социальными благами; есть определенная специфика реализации правомочия обращаться в случае необходимости за государственной защитой служебной инфрормации).

Субъективные права государственных и муниципальных служащих на участие в управлении информационными процессами фриксируются в самых различных законодательных и подзаконных актах. При этом, разумеется, какие-то права имеются у всех без исключения государственных и муниципальных служащих, а какими-то наделены только некоторые из них ${ }^{3}$. В связи с этим отдельные авторы предлагают различать должностные права и обязанности, которые определяют полномочия по конкретной должности, и общие права и обязанности, установленные для государственных гражданских служащих, военнослужащих, сотрудников правоохранительной службы независимо от замещаемых ими должностей.

\footnotetext{
${ }^{3}$ См.: Василенко А.И. Права государственных служащих как основа их правового статуса по российскому законодательству // Юридический мир. - 2009. - № 1. - С. 196.
}

Следует сказать, что специфическими особенностями модернизации профессиональной деятельности и муниципальной службе выступают: публичность; направленность на реализацию инновационных функций государства, местного самоуправления; властный, административноправовой характер служебной деятельности; особая организационная структур модернизации характеризующаяся неотделимостью служебной деятельности от Стратегии инновационного развития; наличие прямой административно-правовой связи между государством, местным самоуправлением, их органами и служащим и в соответствии с инновационным развитием России.

В настоящее время особое значение в современных условиях приобретенной инновационного и правового процесса в системе обеспечения эффективности модернизации деятельности государственных и муниципальных служащих.

Государственная и муниципальная служба базируются в части административно-правового регулирования на общих принципах и основаниях, исходя из которых они получают нормативное закрепление. Почему? Видимо, потому, что муниципальная служба и государственная служба, согласно распространенной точке зрения, являются видами публичной службы. Естественно, муниципальная служба формируется в сорере публичной власти и функционирует как публичная служба, наряду с государственной фредеральной и государственной субъективной видами публичной службы. Серьезным недостатком административно-правового регулирования является отсутствие поиска новой, хоть какой-либо связи между государственной и муниципальной службами. Это изолирует последнюю от влияния государственной службы, использования эфрфективного опыта единых принципов организации и деятельности, является препятствием для ротации кадров, для служебной карьеры муниципальных служащих и для развита инновационной служебной деятельности управленческих кадров.

Конечно, единство и целостность государственной и муниципальной службы может находить воплощение принципов в организации и фрункционирования, институционального взаимодействия и структурного оформления, регламентации правового статуса государственных и муниципальных служащих, а также и многих других вопросов. Ряд авторов приводят доводы в пользу объединения этих институтов. Так, В.В. Еремян указывает на властный характер государственной 
и муниципальной службы ${ }^{4}$. «Общим сущностным признаком, объединяющим правовое положение государственных и муниципальных служащих, является форма публичной власти, обеспечивающая единство властных полномочий соответствующих органов публичной власти» ${ }^{5}$.

Необходимость формирования единых правовых подходов к регулированию государственнослужебных и муниципально-служебных отношений заслуживает, с нашей точки зрения, поддержки и одобрения. Таким образом, существуют реальные предпосылки для того, чтобы служебное право РФ регулировало не только государственно-служебные, но и муниципально-служебные отношения.

Говоря о взаимосвязи между государственной и муниципальной службами, не следует исключать инновационно-правовой характер этой взаимосвязи. Прежде всего, государственная гражданская и муниципальная службы имеют наибольшее количество общих информационных черт. Специальные же виды государственной службы имеют ряд инновационных, информационно-правовых особенностей, которые менее применимы к муниципальной службе. В то же время нельзя категорически отрицать информационно-правовую общность муниципальной службы со всеми видами государственной службы, в том числе правоохранительной и военной. Как отмечалось например, государственная так и муниципальная службы относятся к институтам публичного, в том числе информационного права.

В силу этого они имеют много общего, так как основной целью функционирования государственной и муниципальной службы является обеспечение в информационном обществе прав и свобод человека и гражданина. Оба эти вида публичной службы, обеспечивая информационно-властные полномочия го управленческие функции, осуществляются на профессиональной основе кадровым корпусом государственных и муниципальных служащих, имеющих по своей информационной природе немало общего и особенного.

Ряд вопросов (принципы государственной и муниципальной службы, право равного доступа на государственную и муниципальную службы, исчис-

\footnotetext{
${ }^{4}$ См.: Еремян В.В. Взаимосвязь государственной гражданской и муниципальной службы как двух видов публичной службы и профессиональной деятельности (к постановке проблемы) // Право и политика. - 2006. - № 5. - С. 63.

${ }^{5}$ См.: Козбаненко В.А. Правовое обеспечение статуса государственных и муниципальных служащих: общее и особенное // Государство и право. - 2003. - № 1. - С. 12.
}

ление стажа государственной и муниципальной служб, фрормы денежного содержания государственных и муниципальных служащих и некоторые другие) могут иметь единое правовое регулирование не только для государственной муниципальной, но и для всех видов публичной службы.

Однако, приходится констатировать, что современное законодательство о государственники муниципальной службе пошло по пути расхождения не только этих институтов, но и безучастного отношения к их информационно-правовому и инновационно-административному характеру. В пояснительной записке к законопроекту о муниципальной службе было указано, что принципиальным положением законопроекта, отличающим статус муниципальных служащих от статуса государственных гражданских служащих РФ, является то, что замещение должностей муниципальной службы осуществляется на основе

трудового договора (контракта), а не служебного контракта, как это предусмотрено для государственных гражданских служащих РФ.

Между тем суть административной реформы в ссрере публичной службы как раз и сводилась к отказу от регулирования служебных отношений нормами трудового права и переводу всего служебного законодательства в сфреру права административного, что должно было привести к формированию построенной на общих основаниях единой подотрасли служебного права. Новый же закон о муниципальной службе фриксирует особый, публичный характер служебной деятельности муниципальной службы по большей части чисто формально, не затрагивая вообще информационно-правовой аспект службы. В целом же существующий диспозитивный (дозволительный) режим регулирования муниципальной службы нормами трудового права не соответствует публично-правовой природе этого института.

Видимо, в перспективе, будет сформирована законодательная база, которая в целом урегулирует инфрормационно-правовую сферу публичной службы РФ. В настоящее время в российской правовой науке мало используется принятый в общемировой правовой практике термин «информационная открытость публичной службы».

Вместе с тем давно назрела необходимость введения в российское право понятия, объединяющего все виды службы, направленные на достижение целей социального управления в информационном обществе. Необходимость такого нововведения отмечают многие ученые. 
В свою очередь, публичная служба включает в себя профессиональную деятельность по исполнению полномочий в информационной сфере субъектов права: федеральных органов и органов государственной власти субъектов РФ, органов местного самоуправления и образуемых ими органов, а также публичных объединений, фондов, учреждений, организаций и т.п.

Таким образом, инновационно-административный и информационно-публичный характер должен объединять весь аппарат государственного управления и включать в себя профессиональную деятельность по исполнению полномочий в инновационно-правовой, информационных сорерах различных субъектов публичного права. А именно: Российской Федерации в целом, субъектов РФ, фредеральных органов власти, органов государственной власти субъектов РФ, органов местного самоуправления и образуемых ими публичных учреждений и организаций. Однако в таком контексте публичная служба ставится впервые и не во всем бесспорно ${ }^{6}$.

Если правовой статус государственных и муниципальных служащих действительно имеет много общего, то информационно-правовое положение работников образуемых органами публичной власти предприятий и учреждений, с нашей точки зрения, достаточно существенно от него отличается. Информационно-правовыми признаками, объединяющими служащего, например, фредерального органа государственной власти и государственного учреждения являются публичный характер их деятельности и причастность к реализации государственных функций. Однако все остальные выделенные выше специфические признаки государственной служебной деятельности (наличие властных полномочий, особая организационная структура, наличие прямой публично-правовой связи между государством и государственным служащим) отсутствуют.

Думается, что на современном этапе нет объективных предпосылок для выведения работников образуемых органами информационно-публичной власти предприятий и учреждений из-под частноправового регулирования и лишения их трудоправового статуса. Соответственно, в системе публичной службы тогда можно выделить чисто служебно-правовые отношения, регулируемые публичным правом, и трудоправовые, регулируемые

\footnotetext{
${ }^{6}$ Костенников М.В. К вопросу о некоторых актуальных проблемах административного права // Право и политика. 2013. - № 5. - C. 167.
}

частным правом. В таком случае возникает закономерный вопрос о соотношении понятий «публичноинформационная служба» и «аппарат управления государством». Эти понятия соотносятся как часть и целое. Публично-информационная служба, так же как и государственная и муниципальная, является только частью аппарата государственного, одним из способов реализации функций государства и достижения целей управления обществом.

Публичная служба, с нашей точки зрения, должна базироваться в целом на тех же принципах, что и государственная, которые сформулированы в Федеральном законе от 27 мая 2003 г. «О системе государственной службы Российской Федерации». Вместе с тем, помимо указанных в нем принципов: фредерализма; законности; приоритета прав и свобод человека, - можно выделить несколько принципов, на которых должна базироваться именно публично-информационная служба РФ. Это принципы: 1) единства системы публичной службы в Российской Федерации; 2) независимости всех ее компонентов; 3) равенства всех публичных служащих, независимо от рода их службы, включая информационно-родовое отличие.

Важным представляется также принцип равного доступа граждан к публичной службе. В Конституции РФ закреплено право граждан на доступ только к государственной службе (ч. 4 ст. 32). Во многом это связано с тем, что в 1993 г., когда была принята Конституция, понятие «государственная служба» трактовалось шире, чем теперь, во многом совпадая со сфрерой публичной службы. Но и тогда данный пункт не закреплял право на доступ к службе в органах местного самоуправления, которое, согласно ст. 12 Конституции, не входит в систему органов государственной власти. Вместе с тем целесообразно закрепление права граждан РФ на службу вообще. Смысл данной нормы заключается в конституционном закреплении одного из способов осуществления гражданами РФ права участвовать в управлении государством. Закрепление права граждан на службу в общественных, коммерческих и вообще в негосударственных организациях не способствует реализации этой цели. Право на службу в таких учреждениях уже закреплено ст. 37 Конституции РФ, гарантирующей свободу труда.

Конечно, при поступлении на государственную (муниципальную) службу гражданин России одновременно реализует возможность свободного выбора профрессиональной трудовой деятельности и относящееся к группе политических конституционных прав право на равный доступ к государственной 
службе. При этом закрепление права на равный доступ к государственной службе в качестве отдельного конституционного права лишний раз подчеркивает своеобразие данного вида трудовой деятельности. Поэтому можно говорить о том, что свобода распоряжаться своими способностями к труду в данном случае реализуется особым способом - использованием права на равный доступ к государственной (муниципальной) службе.

Наряду с принятием единого законодательного акта, направленного на регулирование публичной службы РФ, необходимость регулирования служебно-информационной и всей инновационной деятельности служащих не должно вызывать сомнения ученых различных правовых школ. На первоначальном этапе возможно принятие базового федерального закона о публично-инфрормационной службе, регулирующего только наиболее общие вопросы взаимосвязи все видов публичной служебно-информационной деятельности. Впоследствии, однако, целесообразным выглядит разработка такого комплексного документа, как служебно-административный кодек.

Для государственной службы, как и для службы муниципальной, характерно преобладание императивного режима информационно-правового, равно как и административно-правового регулирования: разрешено только то, что прямо указано в законе. Поэтому в рамках модернизации, в части развития правового обеспечения эфффективности модернизации государственной и муниципальной службы, необходимо реализовать позитивный потенциал информационно-правового регулирования складывающихся в этих сфрерах отношении на основе их детальной регламентации нормами и институтами главным образом административного права, с помощью информационного и других сравнительно разных отраслей права ${ }^{8}$.

Формулируя единые подходы к настоящему правовому регулировании государственной и муниципальной службы, необходимо иметь в виду, что при несомненном сходстве (в особенности между государственной гражданской и муниципальной службами) эти виды служебной деятельности имеют и определенные отличия. Они проистекают не только из территориального масштаба, но и из самой сферы

\footnotetext{
${ }^{7}$ См.: Костенников М.В., Куракин А.В. Актуальные проблемы административного права. - М., 2013. - С. 82.

${ }^{8}$ См.: Куракин А.В. Административно-правовое регулирование этического поведения государственных гражданских служащих и обеспечение их надлежащего служебного поведения // Административное и муниципальное право. - 2012. - № 5. - С. 56.
}

инновационной, информационно-правовой, властноуправленческой деятельности. В том числе, из функциональной специфики, особенностей компетенции и полномочий государственных органов либо органов местного самоуправления.

Следует высказать мнение о сохранении информационной сущности при разделении государственной службы в России на несколько уровней, в частности на федеральную государственную службу, государственную службу субъектов РФ и муниципальную службу. Вряд ли надо сомневаться в информационном единстве муниципальной службы и государственной гражданской службы. Конечно, даже с позиций административно-правовой доктрины муниципальная служба тесно связана с государственной, но все же не является ее составной частью.

Для муниципальной службы характерны только первые три признака: 1) публичность; 2) направленность на реализацию функций государства; 3) властный характер служебной деятельности. Четвертый же и пятый признаки применительно к муниципальной службе видоизменяются, причем это изменение носит достаточно принципиальный характер ${ }^{9}$.

Муниципальная служба направлена в первую очередь на решение вопросов местного значения, а не на реализацию функций государства. Однако, с нашей точки зрения, это отличие не имеет принципиального характера, так как вопросы местного значения являются сферой ведения, переданной местному самоуправлению государством для самостоятельного решения исключительно в силу большей эффективности их реализации на местном уровне.

В глобальном смысле процесс решения вопросов местного значения является особым способом реализации общегосударственных задач.

Особенности организационной структуры государственной службы предопределены ее неразрывной связью с таким институтом, как информационное общество. Муниципальная служба связана не только с государством, сколько с муниципальным образованием. Однако ни по масштабам организации, ни по объему информационной деятельности, ни по долговременности существования ни одно, даже самое крупное муниципальное образование не может сравниться с любым государственно-территориальном образованием. Включение государственного служащего в систему государственного

\footnotetext{
9 См.: Куракин А.В. Принципы государственной гражданской службы в механизме противодействия коррупции // Административное и муниципальное право. - 2012. - № 9. - С. 23.
} 
управленческого аппарата позволяет строить новые административно-правовые отношения с ним на принципах стабильности, информационности, характеризующемся тем, что в течение всей служебной карьеры служащий может осуществлять свою деятельность в различных структурных подразделениях и государственных органах, при этом будучи уверенным в сохранении своего информационно-правового статуса.

Итак, различные виды служебной деятельности характеризуются различным соотношением императивных и диспозитивных начал в инновационной сфере. Наибольший объем императивного регулирования характерен для государственной военной службы, а наименьший - для муниципальной. Все это порождает вопрос о соотношении публично-правового и частноправового регулирования указанных общественных отношений в рамках единой модели административно-правового обеспечения эффрективности модернизации профессиональной деятельности управленческих кадров.

\section{Библиографический список:}

1. Василенко А.И. Права государственных служащих как основа их правового статуса по российскому законодательству // Юридический мир. - 2009. - № 1.

2. Еремян В.В. Взаимосвязь государственной гражданской и муниципальной службы как двух видов публичной службы и профрессиональной деятельности (к постановке проблемы) // Право и политика. - 2006. - № 5.

3. Козбаненко В.А. Правовое обеспечение статуса государственных и муниципальных служащих: общее и особенное // Государство и право. - 2003. - № 1.

4. Костенников М.В., Куракин А.В., Марьян А.В. Административно-правовое регулирование противодействия коррупционным рискам в системе государственной службы. - Домодедово, 2011.

5. Куракин А.В. Принципы государственной гражданской службы в механизме противодействия коррупции // Административное и муниципальное право. - 2012. - № 9.

6. Куракин А.В. Административно-правовое регулирование этического поведения государственных гражданских служащих и обеспечение их надлежащего служебного поведения // Административное и муниципальное право. - 2012. - № 5.

7. Костенников М.В. К вопросу о некоторых актуальных проблемах административного права // Право и политика. - 2013. - № 5. - С. 167.

8. Костенников М.В., Куракин А.В. Актуальные проблемы административного права. - М., 2013.

\section{References (transliteration):}

1. Vasilenko A.I. Prava gosudarstvennyh sluzhashih kak osnova ih pravovogo statusa po rossiiskomu zakonodatel'stvu // Yuridicheskii mir. — 2009. —№ 1.

2. Eremyan V.V. Vzaimosvyaz' gosudarstvennoi grazhdanskoi i municipal'noi sluzhby kak dvuh vidov publichnoi sluzhby i professional'noi deyatel'nosti (k postanovke problemy) // Pravo i politika. — 2006. — № 5.

3. Kozbanenko V.A. Pravovoe obespechenie statusa gosudarstvennyh i municipal'nyh sluzhashih: obshee i osobennoe // Gosudarstvo i pravo. —2003. — № 1.

4. Kostennikov M.V., Kurakin A.V., Mar'yan A.V. Administrativno-pravovoe regulirovanie protivodeistviya korrupcionnym riskam $v$ sisteme gosudarstvennoi sluzhby. - Domodedovo, 2011.

5. Kurakin A.V. Principy gosudarstvennoi grazhdanskoi sluzhby $v$ mehanizme protivodeistviya korrupcii // Administrativnoe i municipal'noe pravo. — 2012. — № 9.

6. Kurakin A.V. Administrativno-pravovoe regulirovanie eticheskogo povedeniya gosudarstvennyh grazhdanskih sluzhashih i obespechenie ih nadlezhashego sluzhebnogo povedeniya // Administrativnoe i municipal'noe pravo. — 2012. — № 5.

7. Kostennikov M.V. K voprosu o nekotoryh aktual'nyh problemah administrativnogo prava // Pravo i politika. 2013.- № 5. - S. 167.

8. Kostennikov M.V., Kurakin A.V. Aktual'nye problemy administrativnogo prava. — M., 2013. 